\title{
Gradhiva
}

GRADHI

Revue d'anthropologie et d'histoire des arts

$10 \mid 2009$

Présence africaine

\section{Présence Africaine. Une tribune, un mouvement, un réseau}

Sarah Frioux-Salgas

\section{(2) OpenEdition}

1 Journals

Édition électronique

URL : http://journals.openedition.org/gradhiva/1475

DOI : 10.4000/gradhiva.1475

ISSN : 1760-849X

Éditeur

Musée du quai Branly Jacques Chirac

Édition imprimée

Date de publication : 4 novembre 2009

Pagination : 4-21

ISBN : 978-2-35744-012-8

ISSN : 0764-8928

\section{Référence électronique}

Sarah Frioux-Salgas, "Présence Africaine. Une tribune, un mouvement, un réseau », Gradhiva [En ligne], 10 | 2009, mis en ligne le 04 novembre 2009, consulté le 10 décembre 2020. URL : http:// journals.openedition.org/gradhiva/1475; DOI : https://doi.org/10.4000/gradhiva.1475 


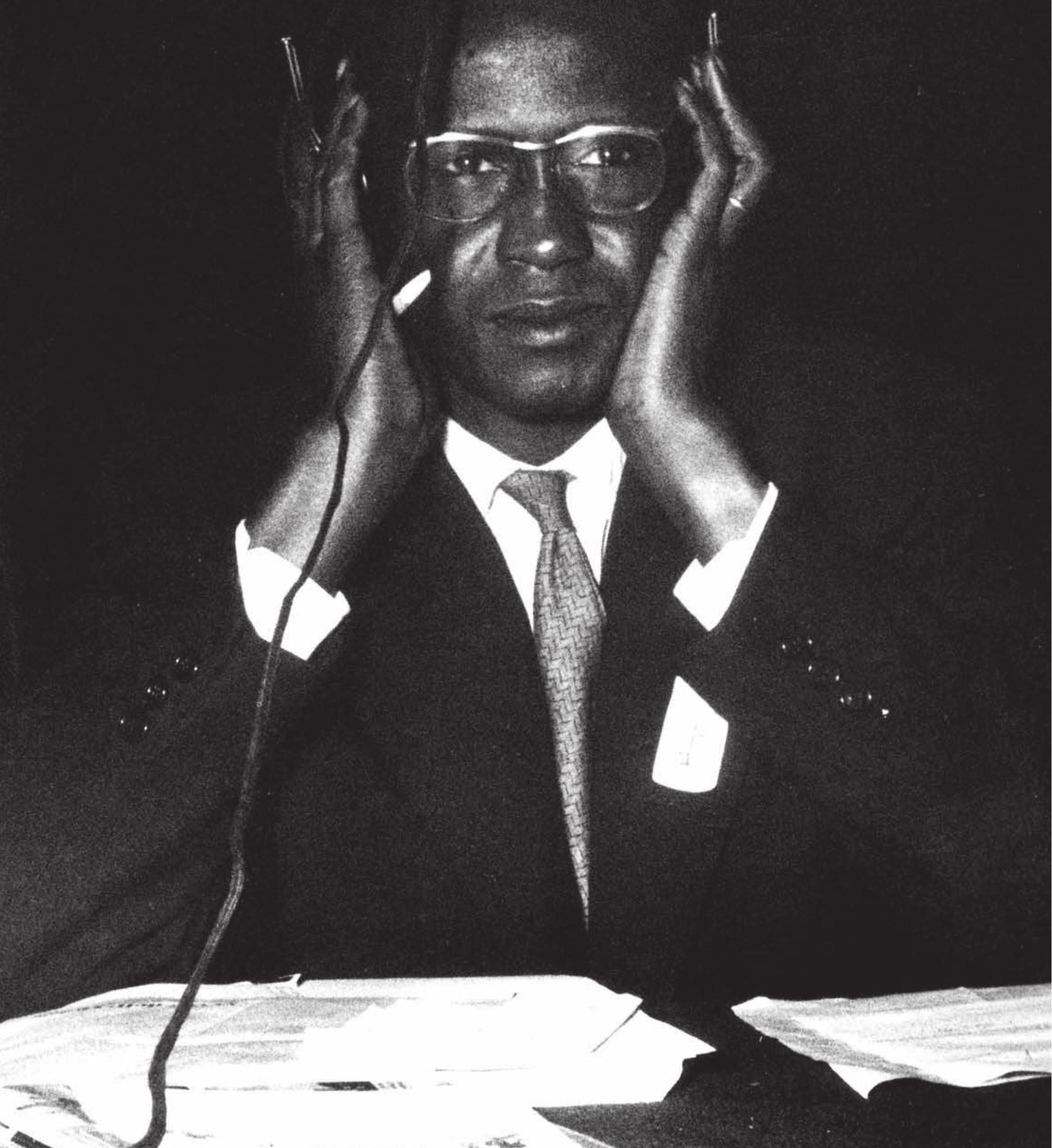




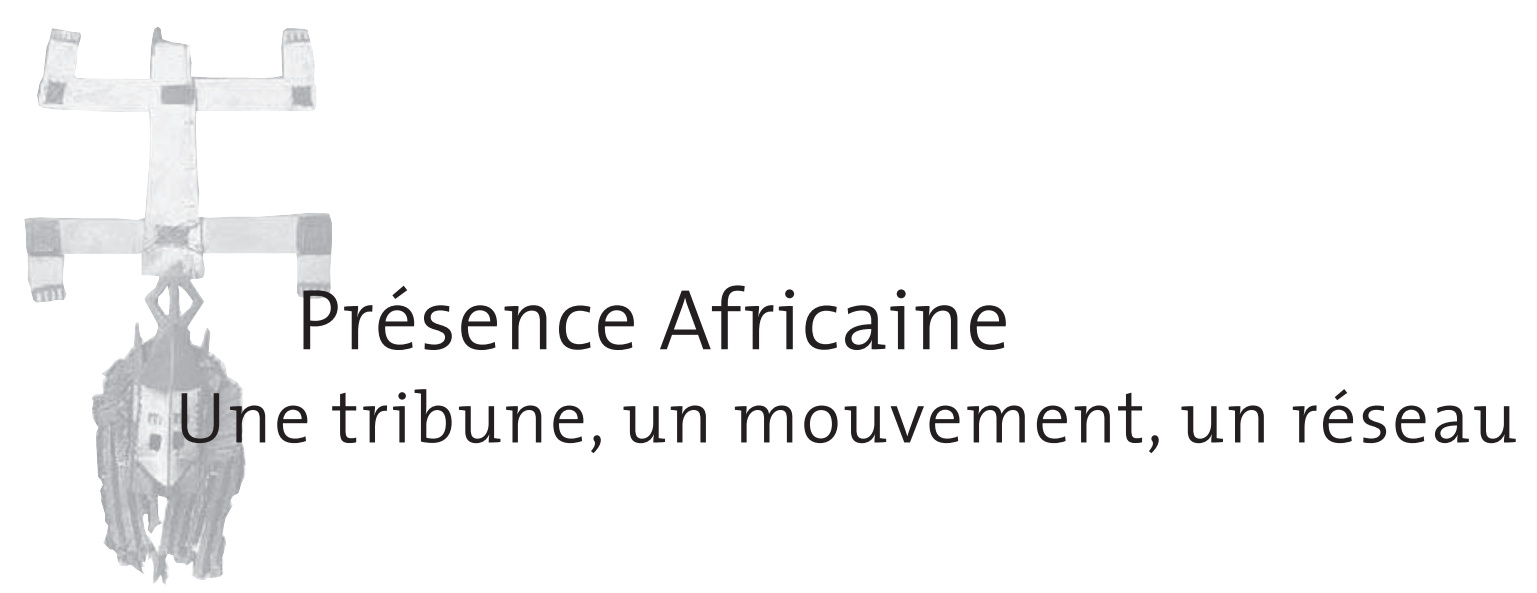



Fig. 1 Alioune Diop, 1956 ๑) Présence Africaine.

- $\bullet$

1. Intellectuel et homme politique sénégalais. Né à Saint-Louis, au Sénégal, le 10 janvier 1910 dans une famille musulmane, il se convertit au catholicisme. Il étudie les lettres classiques à Alger, où il rencontre Albert Camus, puis à Paris. Après avoir enseigné, il est nommé chef de cabinet du gouverneur de l'Afrique occidentale française (AOF). En 1946, il est élu sénateur SFIO, fonction qu'il quitte en 1948 pour se consacrer à Présence Africaine. II meurt le $1^{\text {er mai } 1980 .}$
En 2006, lors du colloque "Que faire des "postcolonial studies" " (Smouts 2007), Georges Balandier rappelait la nécessité d'établir une généalogie du postcolonial. Les études postcoloniales proposent une démarche critique qui s'intéresse aux conditions de la production culturelle des savoirs sur Soi et sur l'Autre et à la capacité d'initiative et d'action des opprimés dans un contexte de domination (ibid. : 33). Dès 1947, le mouvement Présence Africaine, qui naît autour d'une revue créée par Alioune Diop ${ }^{1}$, préfigure ces questionnements, faisant de ce mouvement l'une des références incontournables de la pensée postcoloniale. Ainsi, sept ans avant la conférence de Bandung, Alioune Diop rassemble autour de lui des intellectuels français, africains, antillais et américains pour proposer une autre vision du monde, affirmer la présence des dominés dans l'histoire et dénoncer le racisme et la colonisation. Cette entreprise culturelle a joué un rôle majeur dans l'histoire politique et culturelle des intellectuels noirs francophones, anglophones et lusophones.

Qu'est-ce que Présence Africaine? C'est à la fois une revue, une maison d'édition, fondée par Alioune Diop en 1949, et une librairie, qu'il ouvre en 1962, toutes trois à Paris. Depuis, les activités éditoriales de Présence Africaine n'ont d'ailleurs pas cessé. Les éditions ont publié le philosophe Valentin Yves Mudimbe, le prix Nobel de littérature Wole Soyinka (1986), l'écrivain Daniel Maximin, le lauréat du prix Renaudot Alain Mabanckou (2006)... Mais Présence Africaine est aussi une tribune, un mouvement, un réseau, qui ont permis à plusieurs courants d'idées liés au «monde noir » de s'exprimer et de débattre. Outre ses activités éditoriales, Alioune Diop organise en effet deux congrès d'écrivains et artistes noirs, à Paris en 1956 et à Rome en 1959, il fonde la Société africaine de culture en 1956 et participe activement à l'organisation du Premier Festival des arts nègres de Dakar en 1966. C'est à cette période, allant de la fondation de Présence jusqu'à la fin 
-

2. «Présence Africaine : une tribune, un mouvement, un réseau », musée du quai Branly, 10 novembre 2009 - 31 janvier 2010.

3. Signalons également le roman de Victor Hugo Bug Jargal (1818). Voir aussi Hoffman 1987-1988.

4. Pour une analyse des échanges politiques et culturels entre l'Afrique, les États-Unis et l'Europe, voir Gilroy 2003. II définit l'Atlantique noir comme une formation culturelle transnationale, lieu d'échanges et de liens au sein duquel se construisent et se déconstruisent sans cesse les cultures noires.

5. Le panafricanisme comme l'expression de la solidarité entre les peuples africains et d'origine africaine, et comme la volonté d'assurer la liberté du continent africain et son développement à l'égal des autres parties du monde.

6. William Edward Burghardt Du Bois participe à la création de l'Association nationale pour le progrès des gens de couleur, dont il dirige le magazine officiel, The Crisis, créé en 1910.

7. Ces journaux sont conservés aux Archives d'outre-mer (AOM) à Aix-en-Provence dans le fonds du Slotfom. Le Service de contrôle et d'assistance en France des indigènes des colonies françaises, attaché à la Direction des services militaires, dirigé par le contrôleur général des troupes indochinoises, fut institué par arrêté du 12 décembre 1923 afin d'assurer la tutelle de tous les sujets ou protégés français originaires des possessions d'outre-mer, mais aussi leur surveillance. des années 1960, que s'intéresse en particulier l'exposition présentée au musée du quai Branly². À la mort d'Alioune Diop, en 1980, sa femme, Christiane Yandé Diop, a repris la direction de Présence. La Société africaine de culture, aujourd'hui Communauté africaine de culture, est dirigée par Wole Soyinka.

Ce numéro de Gradhiva entend mettre en perspective l'héritage historique, politique et intellectuel de Présence Africaine, depuis l'abbé Grégoire jusqu'à Alioune Diop.

\section{Les héritages politiques et intellectuels de Présence Africaine}

L'ouvrage De la littérature des nègres (1808), de l'abbé Grégoire, a rassemblé pour la première fois des textes écrits par des Noirs francophones et anglophones d'Afrique et d'Amérique. Il a ainsi constitué un outil déterminant dans la défense de la cause anti-esclavagiste.

"Ami des hommes de toutes les couleurs ", selon ses propres mots, l'abbé Grégoire a été constamment amené à intervenir dans le débat sur les questions coloniales au XviII et au début du xix ${ }^{e}$ siècle (Benot et Dorigny $2000: 1$ ) : participation active à la Société des Amis des Noirs (Dorigny et Gainot 1998), combats pour l'abolition des inégalités engendrées par le préjugé de couleur ainsi que pour l'abolition de l'esclavage et la reconnaissance de la jeune république d'Haïti. Sans être au sens strict les héritiers de l'abbé Grégoire, les protagonistes de Présence Africaine font écho à sa démarche politiques (voir les articles de Bernard Gainot et d'Anthony Mangeon).

C'est avant tout dans l'histoire de mouvements politiques et intellectuels transnationaux ${ }^{4}$, c'est-à-dire celle de la «fabrication de la diaspora noire " (Gueye 2006), que se situe Présence Africaine. En effet, depuis la révolution haïtienne, ces mouvements ont commencé à définir une identité noire transnationale et à dénoncer le racisme et le colonialisme (voir les articles de Pap Ndiaye et d'Anthony Mangeon). La volonté de Présence Africaine de s'inscrire dans l'histoire du combat panafricain ${ }^{5}$ 'affiche dès le premier numéro de la revue : on y trouve traduits plusieurs extraits de l'œuvre du caribéen Edward Wilmot Blyden, pionnier de l'idéologie panafricaine, mais aussi de la pensée nationaliste africaine. Cette filiation se confirme en 1959 avec la première traduction en français du célèbre ouvrage du leader noir panafricain William Edward Burghardt Du Bois ${ }^{6}$ Les Âmes des peuples noirs. Cette anthologie d'essais, publiée en 1903, est l'une des œuvres majeures de l'histoire politique et littéraire noire américaine.

C'est en traduisant en 1960 Panafricanisme ou communisme? de George Padmore, «saga de la montée des Noirs, de l'esclavage à la liberté à l'échelle mondiale» (Padmore 1956, préface de Richard Wright: 12), que Présence Africaine continue à se positionner comme l'un des porte-paroles du panafricanisme. Cet ouvrage inscrit les indépendances africaines dans une histoire politique et intellectuelle des Noirs qui a commencé en 1802 avec la naissance d'Haïti, premier État noir indépendant. George Padmore, originaire de Trinidad, théoricien et idéologue du panafricanisme politique en Afrique, défend depuis les années 1920 l'idée d'un internationalisme noir. Il diffuse ses idées à travers plusieurs journaux: L'Ouvrier nègre, Bureau international d'information des ouvriers nègres et le Negro Worker ${ }^{7}$. Des documents rassemblés par le Slotfom (Service de liaison avec les originaires des territoires français d'Outre-mer) révèlent ses liens avec les militants africains anticolonialistes français. «L'agitateur nègre américain George 


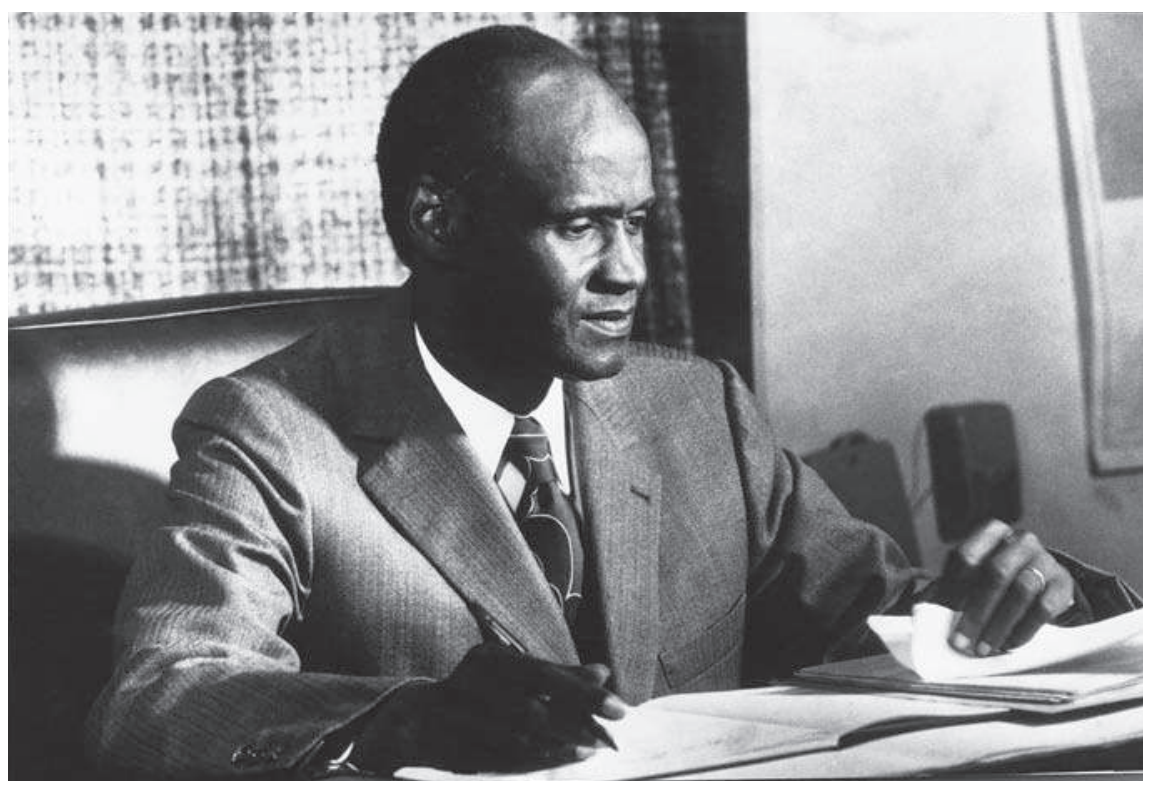

Padmore, secrétaire du comité syndical international des Ouvriers nègres près de l'ISR (Internationale socialiste révolutionnaire), auteur d'une brochure intitulée La Vie et les luttes des travailleurs nègres, dont le texte traduit en français a été imprimé à l'imprimerie de la CGTU à Paris [...] habite Moscou [...]. Depuis 1925, il serait venu deux fois en France, la première fois il se serait rendu à Marseille et la seconde fois, il serait venu à Paris [...]. ${ }^{8}$ "

Si l'histoire politique panafricaine peut sembler essentiellement anglophone, les fondateurs de Présence Africaine sont aussi les héritiers des mouvements politiques africains francophones qui se développent en France et en Afrique dans les années 1920-1930 (voir l'article de Pap Ndiaye). Le Sénégal, d'où est originaire Alioune Diop, est le seul pays d'Afrique noire qui, grâce aux Quatre communes et au conseil colonial, connaît une vie politique relativement libre (Person 1979) ${ }^{9}$. On retrouve ainsi parmi les intellectuels qui participent à la création de Présence Africaine ceux qui, dans les années 1930, luttaient au Sénégal pour la reconnaissance culturelle et la défense des valeurs africaines « authentiques ». En 1932, l'instituteur Mamadou Dia et l'écrivain Abdoulaye Sadji ${ }^{10}$, présents dans le comité de rédaction dès le premier numéro de la revue, créaient le "groupe de Saint-Louis", qui s'exprimait dans le journal Dakar Jeune (ibid. : 81-82). La vie politique sénégalaise était également marquée par l'influence des activités révolutionnaires d'Africains vivant en métropole. Le sénégalais Lamine Senghor, membre du Parti communiste français, a ainsi fondé à Paris en 1926 le Comité de défense de la race nègre (CDRN) et le journal La Voix des Nègres. L'utilisation du mot « nègre " était expliquée dans l'éditorial du premier numéro : "les jeunesses de CDRN se sont fait un devoir de ramasser ce nom où vous le traînez pour en faire un symbole. Ce nom est celui de notre race [...] Nous voulons imposer le respect dû à notre race, ainsi que son égalité avec toutes les races du monde, ce qui est son droit et notre devoir, et nous nous appelons nègre».

Suivront en 1927, avec le soudanais Tiemoko Garan Kouyaté, la Ligue de défense de la race nègre, ainsi que les journaux La Race nègre (1927-1931) et Le Cri des Nègres (1931-1936). Ces activistes parisiens diffusent leurs journaux en Afrique par l'intermédiaire de marins qui partent de Marseille ou de Bordeaux, comme l'atteste le
Fig. 2 Alioune Diop dans les années 1970 ๑) Présence Africaine.

\section{- \\ 8. Slotfom, rapport de Désiré, 2 février 1932, dossier personnel George Padmore. \\ 9. Les Quatre communes regroupaient les villes de Dakar, Gorée, Rufisque et Saint-Louis, dont est originaire Alioune Diop, et fonctionnaient comme les municipalités françaises, avec des maires élus. Leurs habitants y jouissaient ainsi des mêmes droits que ceux de la métropole. Voir Person 1979.}

10. Mamadou Dia, mort en janvier 2009, a été l'un des artisans de l'indépendance du Sénégal. II devient chef du gouvernement sénégalais de 1960 à 1962 . Abdoulaye Sadji participe au projet de revue Découvertes, qui précède la création de Présence Africaine (Archives Michel Leiris, Laboratoire d'anthropologie sociale, $\mathrm{fr} / \mathrm{cdf} /$ las/FML-E 01-01-143], et publie dans Présence Africaine le premier chapitre de son roman Nini, qui paraîtra aux éditions Présence Africaine en 1955. 
- $\bigcirc$

11. AOM, fonds Slotfom, série 3, carton 24. La circulation de la presse noire politique est évoquée dans le roman Banjo de l'écrivain jamaïcain Claude McKay, publié en français en 1932 :

«Le gentleman blanc avait dit au patron que les Noirs qui publiaient la Race Noire faisaient une œuvre anti-française, qu'un pareil journal devrait être interdit et que ceux qui l'éditaient, on devrait [...] les fourrer en prison comme des criminels. Le propriétaire du bar répondit qu'on n'était pas ici en Afrique Occidentale où, lui avait-on dit, les autorités locales avaient interdit la diffusion du Negro World. »

12. AOM, fonds Slotfom, série 3, carton 53. Kouyaté fonde en 1933 la Ligue pour l'indépendance des peuples du Soudan et du Sénégal, qui préconise l'indépendance totale dans une perspective de nationalisme révolutionnaire.

13. Birago Diop est l'auteur du livre à succès Nouveaux contes d'Amadou Koumba, publié aux éditions Présence Africaine en 1958.

14. Ce journal était tiré à trois mille exemplaires en 1934.

15. La Revue du monde noir, $\mathrm{n}^{\circ} 1$ (1931, novembre), n 6 (1932, avril), Paris, éditions de la Revue mondiale, texte bilingue françaisanglais. Existe également sous forme de reproduction en fac-similé, Paris, Jean-Michel Place, 1992.

16. Lettre de Jane Nardal adressée le 27 décembre 1927 à Alan Locke : «C'est pourquoi, lorsque M. Payot, l'éditeur, que j'ai eu l'occasion de connaître, me parla de votre anthologie The New Negro, je l'engageai vivement, après lecture, à la faire traduire et éditer » (Archives Alan Locke à Howard University, Moorland-Spingarn Research Center, Manuscript Division, Alan Locke Papers, box 164-74, folder 25).

17. Son ouvrage majeur, Ainsi parla l'oncle (1928), écrit en français, étudie les fondements à la fois historiques et folkloriques de la culture haïtienne. Il y affirme que les Haïtiens ne sont pas des «Français colorés», mais des hommes nés dans des conditions historiques déterminées et ayant un double héritage, français et africain. II fonde à Port-au-Prince, en 1941, I'Institut d'ethnologie. rapport d'un agent du Slotfom daté du 6 août 1927 : «Samedi après-midi 30 juillet, Senghor et un de ses compatriotes au siège de la ligue de la RN, 43 rue Simplon, ont fait 6 paquets du n 2 de la Race Nègre, chaque paquet contenant 400 exemplaires et les ont expédiés le jour même à Marseille. Une partie sera distribuée à titre de propagande dans la région de Marseille et l'autre envoyée aux colonies de l'AOF. La maison Forestier (photographie) à Dakar a accepté d'être le dépositaire du dit journal et d'en assurer la diffusion ${ }^{11}$. » Kouyaté crée quant à lui en 1932 l'Union des travailleurs nègres $(\mathrm{UTN})^{12}$, dont le but est « d'assurer le développement culturel et l'entraide mutuelle entre les travailleurs nègres de France et des colonies ». En 1934, Alioune Diop et Birago Diop ${ }^{13}$ sont d'ailleurs soupçonnés par le Slotfom de fréquenter à Dakar «les milieux extrémistes, notamment l'UTN ». Cette note laisse supposer qu'Alioune Diop était un lecteur du journal Le Cri des Nègres, devenu l'organe de presse de l'Union des travailleurs nègres ${ }^{14}$; journal qui, depuis sa création en 1931, critiquait violemment l'impérialisme européen, la colonisation, mais aussi la situation des Noirs américains.

Si Alioune Diop évolue donc dans un contexte politique sénégalais contestataire, le projet Présence Africaine s'inscrit également dans le sillage des mouvements littéraires new-yorkais et parisiens qui se sont développés dès les années 1920-1930. Anthony Mangeon brosse dans son article un tableau des principales revues et anthologies qui, à compter du xix siècle, se sont consacrées à la promotion des cultures noires. Il étudie plus particulièrement deux anthologies majeures, relais du mouvement littéraire et artistique d'avant-garde New Negro, né à Harlem dans les années 1920 : The New Negro, An Interpretation de Alain Locke (1925) et Negro Anthology de Nancy Cunard (1934). Les écrivains et poètes Langston Hughes, Zora Neale Hurston, Claude McKay, Counteen Cullen, le comédien Paul Robeson ou encore l'artiste Aaron Douglas peuvent être considérés comme des symboles de cette avant-garde. Le livre d'Alain Locke rassemble des textes littéraires, des essais d'histoire, de sociologie, de critique littéraire, des reproductions d'art, des bibliographies, des partitions musicales, de la littérature orale. Il défend une nouvelle génération d'écrivains qui font de leur origine sociale-leur appartenance à la classe ouvrière - et de leur héritage africain - celui de l'esclavage - la matière de leurs œuvres. Ainsi, dans une Amérique raciste, il regroupe des journalistes, des universitaires, des artistes blancs et noirs. De son côté, Negro Anthology, coordonné par Nancy Cunard (en collaboration avec George Padmore) en 1934, avait une visée plus politique. Tout en exaltant les cultures noires, l'ouvrage s'attache en effet plus particulièrement à dénoncer le racisme et la colonisation.

Ce mouvement intellectuel anglophone influence fortement la jeunesse africaine et antillaise parisienne des années 1930, et en particulier le groupe réuni autour de La Revue du monde noir ${ }^{15}$. Cette revue bilingue franco-anglaise, fondée en novembre 1931 par la martiniquaise Paulette Nardal, avait pour ambition d'une part de "créer entre les Noirs du monde entier, sans distinction de nationalité, un lien intellectuel et moral qui leur permette de mieux se connaître", d'autre part de rejoindre les positions des écrivains du New Negro, qui «expriment tranquillement leur être individuel à la peau noire et sans honte " (Nardal 1932 : 345). Dès 1927, Paulette Nardal s'intéresse avec sa sœur Jane à cette publication et propose aux éditions Payot de traduire l'anthologie The New Negro ${ }^{16}$. Ce projet n'aboutit pas, mais elle en publie plusieurs extraits dans sa revue.

Certains auteurs publiés ou défendus dans La Revue du monde noir participeront plus tard aux activités éditoriales de Présence : le $\mathrm{D}^{\mathrm{r}}$ Jean Price-Mars ${ }^{17}$, 


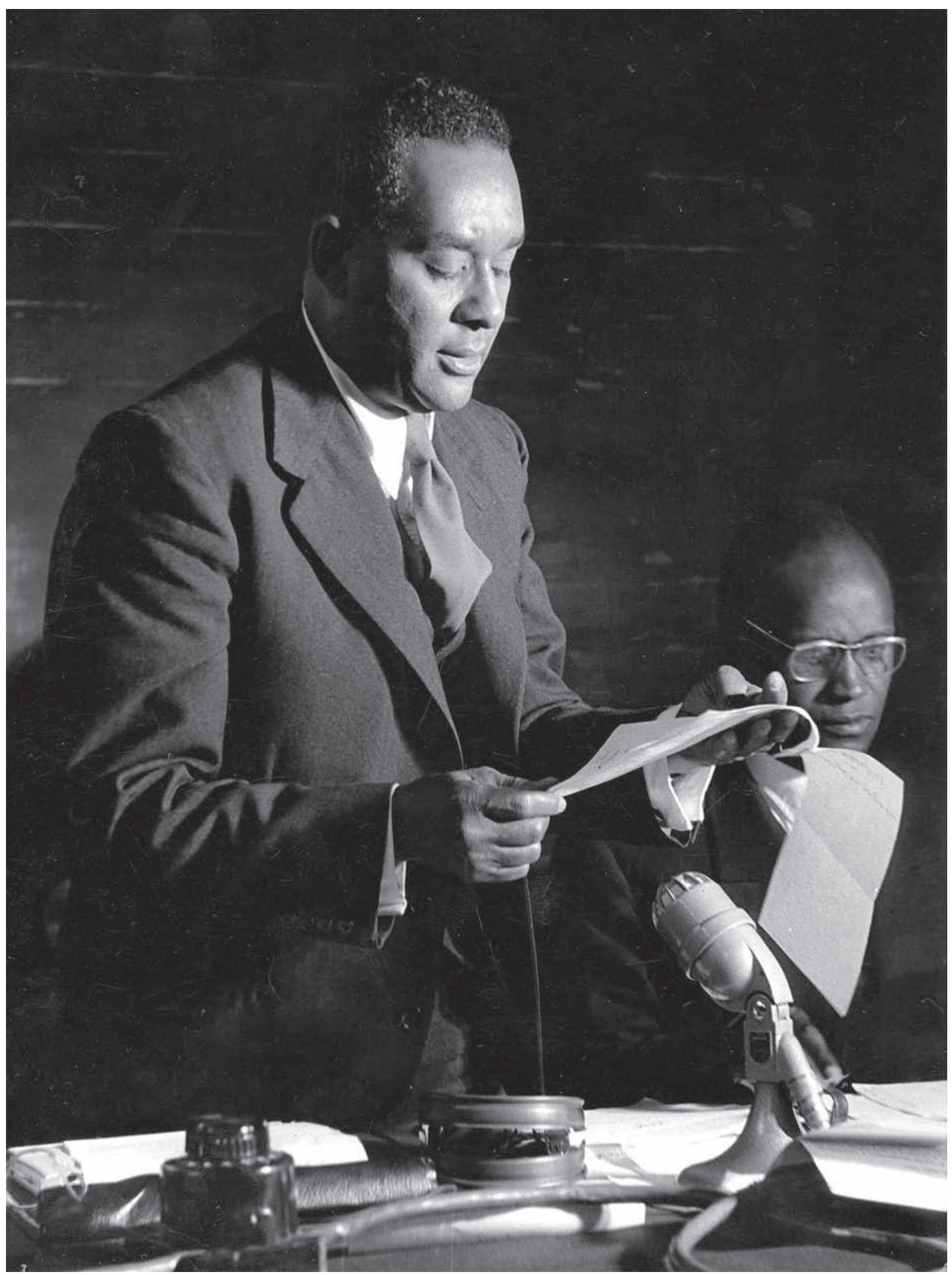

Fig. 3 L'écrivain Richard Wright et Alioune Diop au Premier Congrès international des écrivains et artistes noirs à Paris, septembre 1966 () Présence Africaine. 


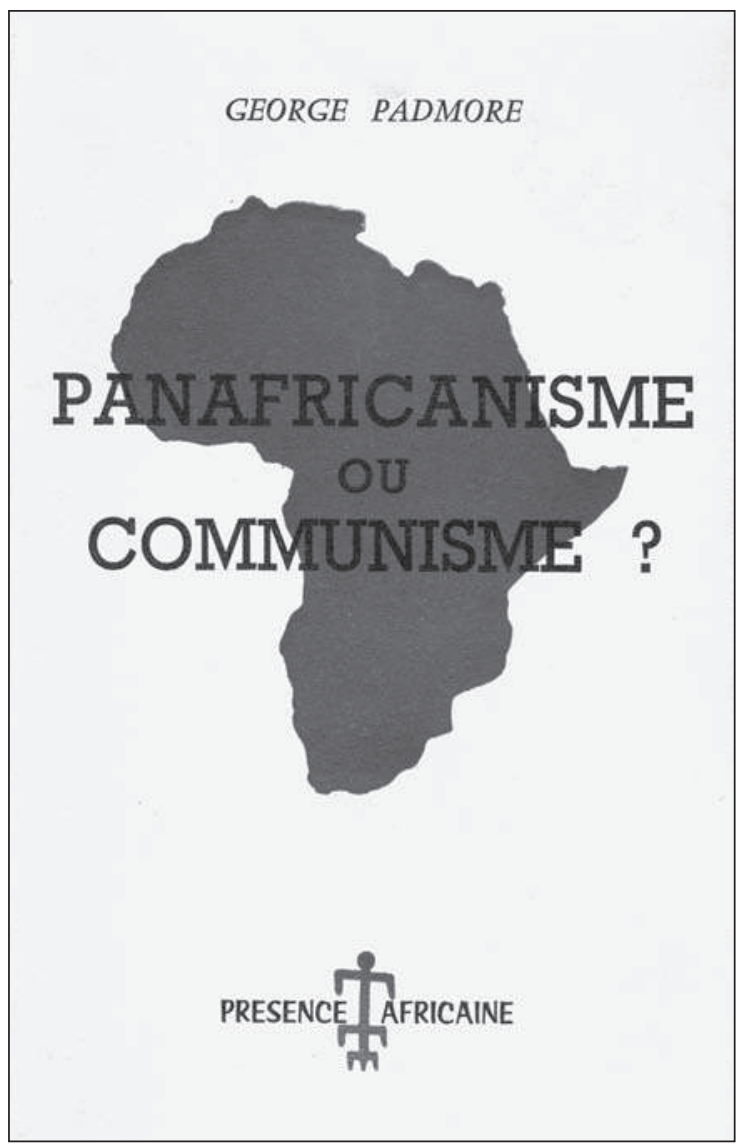

fondateur du mouvement indigéniste haitien, qui présida le Premier Congrès des écrivains et artistes noirs de 1956, le poète martiniquais Gilbert Gratiant, l'écrivain René Maran, lauréat du prix Goncourt en 1921, ainsi que le professeur Louis Thomas Achille.

À la même époque émerge le mouvement littéraire de la "négritude», représenté par le martiniquais Aimé Césaire, le sénégalais Léopold Sédar Senghor et le guyanais Léon-Gontran Damas. La négritude apparaît donc dans ce contexte d'importantes revendications identitaires et de fortes contestations politiques. La publication du journal L'Étudiant noir (journal de l'Association des étudiants martiniquais en France), en 1935, a marqué les débuts du mouvement. Plusieurs rédacteurs de cet unique numéro, tels que Gilbert Gratiant ou Léonard Sainville, seront des compagnons de route de Présence. Présence Africaine revendique surtout cet héritage intellectuel francophone et ambitionne d'en être le porte-parole. Césaire et Senghor soutiendront la revue dès ses débuts ${ }^{18}$ et participeront à sa notoriété. Les éditions Présence Africaine rééditeront, en 1962, Pigments de Léon-Gontran Damas (première parution en 1937) et, en 1956, Cahier d'un retour au pays natal d'Aimé Césaire (première parution en 1939).

Ainsi, à sa parution en 1947, le premier numéro de la revue poursuit un combat politique et intellectuel entamé au XIX ${ }^{e}$ siècle.
Fig. 4 Panafricanisme ou communisme? La prochaine lutte pour l'Afrique de George Padmore, 1960. Traduction de Pan-Africanism or Communism? The Coming Struggle for Africa publié à Londres en 1956.
- $\bullet$

18. Aimé Césaire et Léopold Sédar Senghor étaient dans le comité de patronage du premier numéro.

\section{La naissance de la revue Présence Africaine}

Les aspirations et la stratégie intellectuelle d'Alioune Diop, sa volonté de rassembler des intellectuels noirs, blancs, francophones, lusophones et anglophones, se dessinent clairement avant la création de la revue et de la maison d'édition. Georges Balandier se souvient de son premier séjour à Dakar en 1946 : «Tout m'attirait en lui, son élégance naturelle, sa générosité, sa double culture, sa volonté patiente qui ne redoutait ni les obstacles ni les défis : être catholique bien que fils de lettré musulman, parler à des communautés séparées par les différences, l'inégalité et les discriminations. Nous avons discuté chaque soir, et il fut ainsi mon instituteur. Des visiteurs venaient, des notables, des imams dakarois, des politiciens locaux dont le socialiste Lamine Guèye, des hommes de culture» (Balandier 1977: 51-52). On retrouve ce même esprit de rassemblement dans une lettre adressée en 1946 à Michel Leiris au sujet du projet inabouti de la revue Découvertes :

«Découvertes » 2 bis avenue Pasteur Dakar (AOF)

Monsieur,

Nous sommes à Dakar un petit groupe d'amis africains et européens qui songeons à créer un organe de rapprochement entre les uns et les autres. Il ne s'agit pas, une fois de plus, d'une entreprise à caractère politique, mais d'une action sur le plan culturel. L'Afrique Française possède dès à présent des moyens d'expression dans l'ordre politique, syndical ou 
confessionnel. Mais l'Africain doit pouvoir parler en tant que représentant d'une civilisation originale. Il faut que l'Européen le connaisse mieux et en même temps se fasse mieux connaître de lui. Nous avons rencontré jusqu'ici nombre d'Africains dignes de révéler leur richesse et n'ayant aucune possibilité d'y parvenir, ils désirent d'autre part se tenir au courant des grandes tendances de la pensée européenne.

Nous envisageons de créer une revue mensuelle "Découvertes" qui, organisée à la manière des grandes revues françaises, servirait de lieu de rencontre à des Africains et à des Européens. Des hommes de tendances diverses pourraient y discuter librement des problèmes du monde noir. Elle ne se rattacherait à aucune obédience littéraire ou philosophique. Dans ce sens, nous avons songé à constituer un comité de patronage très varié où seraient réunies les personnalités suivantes parmi lesquels vous figurez: MM Rivet: directeur du musée de l'Homme, MM Monod : directeur de l'IFAN, MM Mounier : directeur de la revue «Esprit», MM Sartre : directeur de la revue «Les temps modernes», MM Naville : directeur de "La revue Internationale», RP Maydieur : directeur de la revue «Vie intellectuelle», Albert Camus, Michel Leiris, L. S. Senghor.

Nous aimerions nous assurer de votre autorité et de votre appui, vous représenteriez dans ce comité un des aspects principaux de l'activité intellectuelle en France.

Nous serions très honorés si vous acceptiez cette offre. [...]

Le comité de rédaction : Georges Balandier, Paul Mercier, Dia Cissé Loum, Abdoulaye Sadji, Alioune Diop ${ }^{19}$.

Le comité de patronage proposé ici est presque identique à celui du premier numéro de Présence Africaine. Manquent André Gide, Aimé Césaire, Richard Wright et Paul Hazoumé. Découvertes devait être une revue sénégalaise inspirée par les mensuels français. Présence Africaine ${ }^{20}$ sera une revue culturelle francoafricaine pérenne consacrée à l'Afrique et aux «mondes noirs", fondée et dirigée par un intellectuel africain issu d'un pays colonisé. Dans le texte inaugural de Présence, "Niam n'goura ou la raison d'être de Présence Africaine", Alioune Diop n'évoque pas ce premier projet dakarois. Il préfère rappeler la période de la guerre : «L'idée remonte à 1942-1943. Nous étions à Paris un certain nombre d'étudiants d'outre-mer qui - au sein des souffrances d'une Europe s'interrogeant sur son essence et sur l'authenticité de ses valeurs - nous sommes groupés pour étudier la situation et les caractères qui nous définissaient nous-mêmes. " Élisant cette genèse, il choisit d'ancrer Présence Africaine dans l'histoire des intellectuels noirs et non pas uniquement dans celle des Sénégalais. Le poète malgache Jacques Rabemananjara évoque les rencontres organisées par Alioune Diop sous l'Occupation : "Il y avait là toute une brochette d'ultra-marins : le Dahomey, le Togo, les Antilles, l'Anam et Madagascar; Louis Béhanzin et son alter ego François Amorin, Anoni Santos, Migan Apithy, Guy Tirolien, Albert Beville [... ${ }^{21} . »$

C'est donc à Paris, centre de «la république mondiale des lettres» (Casanova 2008) et du pouvoir colonial, qu'est créée la revue. La composition du comité de patronage témoigne d'un contexte éditorial et intellectuel français favorable à Présence Africaine ${ }^{22}$. Les Temps modernes (Jean-Paul Sartre), Esprit, le Seuil (Emmanuel Mounier), Seghers, Corréa (Maurice Nadeau), puis Maspéro publient alors des auteurs d'Afrique, d'Amérique, des Antilles et de l'océan Indien, engagés ou non (voir l'article de Julien Hage). Alioune Diop, comprenant la nécessité de s'entourer d'intellectuels français pour que le public réserve un bon accueil à Présence Africaine, a recherché leur soutien, comme le montre cette lettre adressée à Jean-Paul Sartre en 1958 :
- -

19. Archives Michel Leiris, Laboratoire d'anthropologie sociale, $\mathrm{fr} / \mathrm{cdf} / \mathrm{las} / \mathrm{FML}-\mathrm{E}$ 01-01-143.

20. Présence Africaine devait pourtant paraître aussi au Sénégal. Une société à responsabilité limitée au capital de 50000 francs CFA fut créée à Dakar pour fonder Présence Africaine. Les associés étaient Robert Delmas (commerçant), Djima N'Diaye, Hadj Liman et Ibrahima Gueye (ébéniste).

21. Hommage à Alioune Diop 1977 : 19. Dans son article «Genèse de la littérature afro-francophone en France entre les années 1940 et 1950 », Katherina Stadler rappelle qu'au sein du Foyer colonial (184, boulevard Saint-Germain), Alioune Diop animait depuis 1942 le Cercle culturel des étudiants coloniaux de Paris, que fréquentaient presque tous ceux qui allaient embrasser la politique dans le cadre de la future Union française. Ce foyer avait été créé par le gouvernement de Vichy pour permettre aux étudiants d'outre-mer de se retrouver en temps de guerre.

22. Présence Africaine aborde cette question dès 1948 à travers deux articles de Jean Caillens $\left(n^{\circ 5} 4\right.$ et 5]: «Culture et civilisation noire à travers l'édition française ». 
C'est pourquoi vous ne serez pas surpris que nous nous adressions encore à vous pour qu'une voix autorisée (la plus autorisée peut-être en Occident) s'élève pour parler d'Aimé Césaire, poète de la négritude. Césaire, je le sais, ne le souhaite pas. Il pense n'avoir pas encore assez produit.

Mais les Africains attendent. Ils ont lu et relu et porté haut dans leur cœur les stances du Cahier, des Armes ou les périodes du Discours. Ils attendent comme un écho. Vous détenez encore, vous Occidentaux (malgré l'effort que personnellement depuis de longues années vous déployez contre racisme et colonialisme), l'autorité de la culture. Tout le monde est habitué à aimer une œuvre et à chercher dans vos propos l'écho de son amour. Parlez donc, afin que se réalise plus rapidement notre accès (l'accès de notre conscience et de notre initiative) aux ressources techniques et politiques de la vie culturelle, de la vie moderne, tout court ${ }^{23}$.

Alioune Diop parvient finalement à rassembler autour de lui des intellectuels africains et européens issus de traditions politiques très diverses qui s'associent dans un combat commun : l'anticolonialisme et la reconnaissance des «cultures noires ». Jean-Paul Sartre, Boris Vian, Alfred Métraux, Albert Camus, Georges Balandier, Théodore Monod, Richard Wright, Aimé Césaire, Léopold Sédar Senghor, Léon-Gontran Damas, René Maran, Pierre Naville, Charles Ratton, Michel Leiris, le père Maydieu, Jacques Howlett ${ }^{24}$ et d'autres s'engagent aux côtés de Présence. En accompagnant Alioune Diop, tous se positionnent visà-vis du public français comme les passeurs des idées défendues par Présence Africaine.

23. Archives Michel Leiris, Laboratoire d'anthropologie sociale, $\mathrm{fr} / \mathrm{cdf} / \mathrm{las} / \mathrm{FML}-\mathrm{E}$ 01-01-110.

24. Dans le premier numéro, Boris Vian traduit en français la nouvelle de Richard Wright Claire étoile du matin; Théodore Monod coordonne le numéro 8-9 «Le monde noir » (1950); Charles Ratton le numéro 10 consacré à l'art africain (1951); Alfred Métraux le numéro 12 consacré à Haïti; Pierre Naville le numéro 13 consacré au travail en Afrique noire (1952). Le philosophe Jacques Howlett s'engage quotidiennement, jusqu'à sa mort, auprès de Présence Africaine.

25. Hommage à Alioune Diop 1977 : 61.

26. Archives Michel Leiris, Laboratoire d'anthropologie sociale, $\mathrm{fr} / \mathrm{cdf} / \mathrm{las} / \mathrm{FML}-\mathrm{E}$ 01-01-113.
Cher Alioune, écrit René Depestre, à l'heure du bilan, ce que j'apprécie le plus en toi, c'est l'homme de dialogue qui, quoique lié à l'idéologie conservatrice du grand poète Sédar Senghor, quoique acquis au messianisme à mon avis douteux de la négritude, a ouvert "Présence Africaine» et tes éditions à d'éminents africanistes soviétiques; à des hommes aussi différents que Fanon, Suret-Canale, Cheikh Anta Diop et Leiris, Aimé Césaire et Bastide, Senghor, Jacques Roumain, J.S. Alexis et J. Rabemananjara, Damas, Guillen, Édouard Glissant et M. J. Herskovits, sans patauger pour autant dans un éclectisme sans rivages ${ }^{25}$.

\section{La mise en place d'un réseau}

Parallèlement à la revue, qui doit s'adresser "à la jeunesse d'Afrique " (A. Diop 1947 : 8). Alioune Diop pense Présence Africaine comme une structure associative devant «aider les jeunesses africaines à mieux s'affirmer par l'étude des questions littéraires, artistiques et sociales pour l'élaboration d'un humanisme nègre au sein du monde ". En avril 1947, il fonde à Dakar l'association Les Amis de Présence Africaine :

L'association exerce son action : 1) au point de vue culturel par la création: a) de sections littéraires (bibliothèques, cercle d'étude, conférences), b) de sections musicales (auditions de morceaux classiques, constitution d'orchestres...), c) de sections théâtrales. 2) au point de vue social par le développement: a) des mouvements de jeunesse (scoutisme, tourisme...), b) des sports (tennis, ping-pong, athlétisme...) [... ${ }^{26}$. 


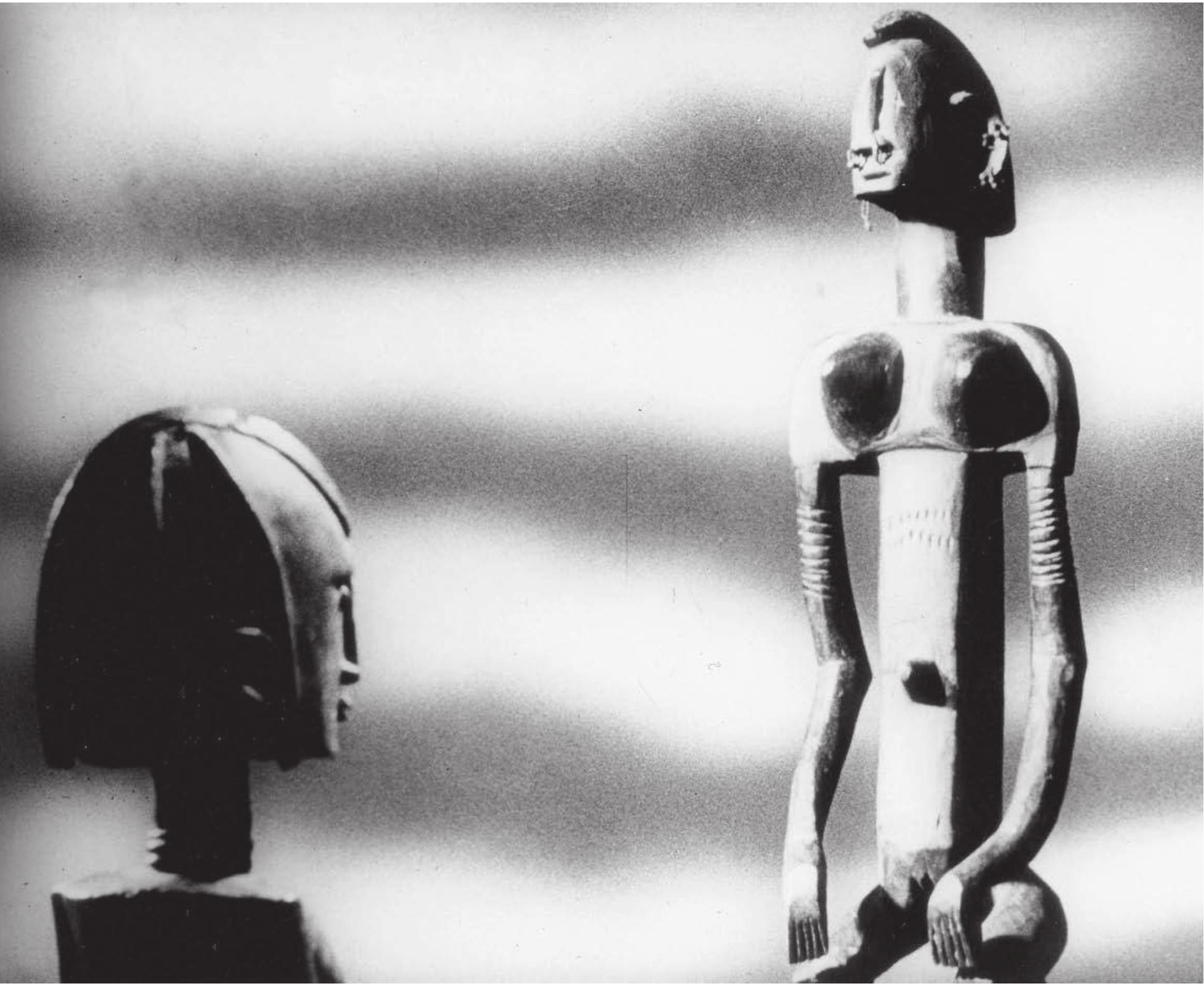

Fig. 5 Photogramme du film Les statues meurent aussi de Chris Marker et Alain Resnais, 1953. Iconothèque de la Cinémathèque française () Présence Africaine.

L'aspect social du projet développé dans le second point nous rappelle qu'en 1947 Alioune Diop était encore un élu politique (SFIO). En revanche, les actions culturelles proposées annoncent les activités parisiennes de Présence Africaine, dont celles de la seconde association, qu'il fonde à Paris et qui confirme l'orientation de ses précédentes démarches dakaroises. Les statuts de l'association parisienne rappellent également sa volonté d'instaurer un dialogue entre les intellectuels africains et européens exprimée dans le projet Découvertes.

Formation et but de l'association [...]. 2) de faciliter les contacts entre intellectuels noirs et blancs, de manière à favoriser l'élaboration d'un humanisme nègre au sein du monde moderne. 3) de travailler 
à mieux faire connaître les valeurs africaines. Art. 2 : Les «Amis de Présence Africaine » exercent leurs actions : 1) par leur participation effective à la revue "Présence Africaine" sous la présidence de son fondateur, Alioune Diop; 2) par la création de cercles d'étude où il serait traité des aspects les plus significatifs des cultures, tant africaines qu'européennes ; 3) par l'organisation de conférences, de concerts, de spectacles, d'expositions susceptibles de permettre au monde africain de se faire mieux connaître et d'apporter sa contribution à l'édification d'une civilisation nouvelle, capable d'unir dans une humaine fraternité des hommes qui jusqu'ici s'ignorent ; 4) par l'établissement d'un club qui serait ouvert à tous les intellectuels et tous les étudiants d'origine africaine ou de descendance africaine, ainsi qu'à tous les amis de Présence Africaine $[. . .]^{27}$.

Autrement dit, dès le départ, Alioune Diop envisageait de mettre en place, non seulement une maison d'édition, mais aussi un réseau de réflexion et d'idées. Le Premier Congrès des écrivains et artistes noirs, organisé en 1956 à Paris, en est l'exemple le plus marquant. Alioune Diop réussit à rassembler pour la première fois des intellectuels noirs de divers continents et d'obédiences politiques différentes afin de dresser l'inventaire commun des cultures noires, de réfléchir à leur rôle dans la société et d'analyser "les responsabilités de la culture occidentale dans la colonisation et le racisme » (Premier Congrès international des écrivains et artistes noirs 1956) (voir l'article de Romuald Fonkoua et Marc-Vincent Howlett, l'entretien avec Daniel Maximin, puis le témoignage de René Depestre).

Cette manifestation symboliquement et politiquement spectaculaire est précédée de travaux préparatoires dans lesquels s'impliquent les intellectuels noirs francophones, anciennes et nouvelles générations, comme l'indique une note de la rédaction dans le numéro 7 (1956) de la revue :

Le 27 avril dernier, Cheikh Anta Diop inaugurait salle D des Sociétés Savantes la série de conférences que nous organisons tous les vendredis (nos lecteurs sont priés de trouver chaque jeudi dans Le Monde la confirmation des dates de ces conférences) dans le cadre de la préparation du Congrès des Écrivains et Artistes Noirs. Son exposé portait sur les origines nègres de la civilisation égyptienne. D'autres conférenciers ont depuis pris la parole: G. Gratiant sur la place du créole dans l'expression antillaise; É. Glissant sur l'avenir de la littérature noire. Au moment où nous mettons sous presse, L. S. Senghor a traité de la littérature orale négro-africaine pour être bientôt suivi par Aimé Césaire (colonialisme et culture), Habib Benglia, R. Wright, B. Traore, K. Fodeba et René Depestre. Pour clore le cycle de conférences, une conférence de presse, sur le sens du Congrès, sera donnée le 6 juillet.

Ces réunions ne sont pas nouvelles. En 1955, Alioune Diop invitait déjà Michel Leiris à participer à l'une des réunions que Présence organisait régulièrement :

- -0

27. Archives Michel Leiris, Laboratoire d'anthropologie sociale, $\mathrm{fr} / \mathrm{cdf} / \mathrm{las} / F M L-E$ 01-01-110.

28. Lettre d'Alioune Diop adressée à Michel Leiris le 16 mars 1955. Archives Michel Leiris, Laboratoire d'anthropologie sociale, $\mathrm{fr} / \mathrm{cdf} /$ las/FML-E 01-01-80.
Nous organisons tous les jeudis à 20 h 45 un entretien confié à un spécialiste ou à un étudiant africain. Cet entretien peut porter sur un sujet ethnologique, social, économique, culturel. Il doit cependant être conçu de telle sorte qu'il puisse concerner toute l'Afrique (son passé et son avenir) et intéresser notre auditoire restreint (30-50 personnes) composé essentiellement d'étudiants africains. L'exposé est suivi d'échanges de vue sur quelques-unes des questions soulevées par l'auteur. Nous vous serions obligés de nous indiquer s'il vous serait possible de venir passer une soirée avec nous [... ${ }^{28}$. 


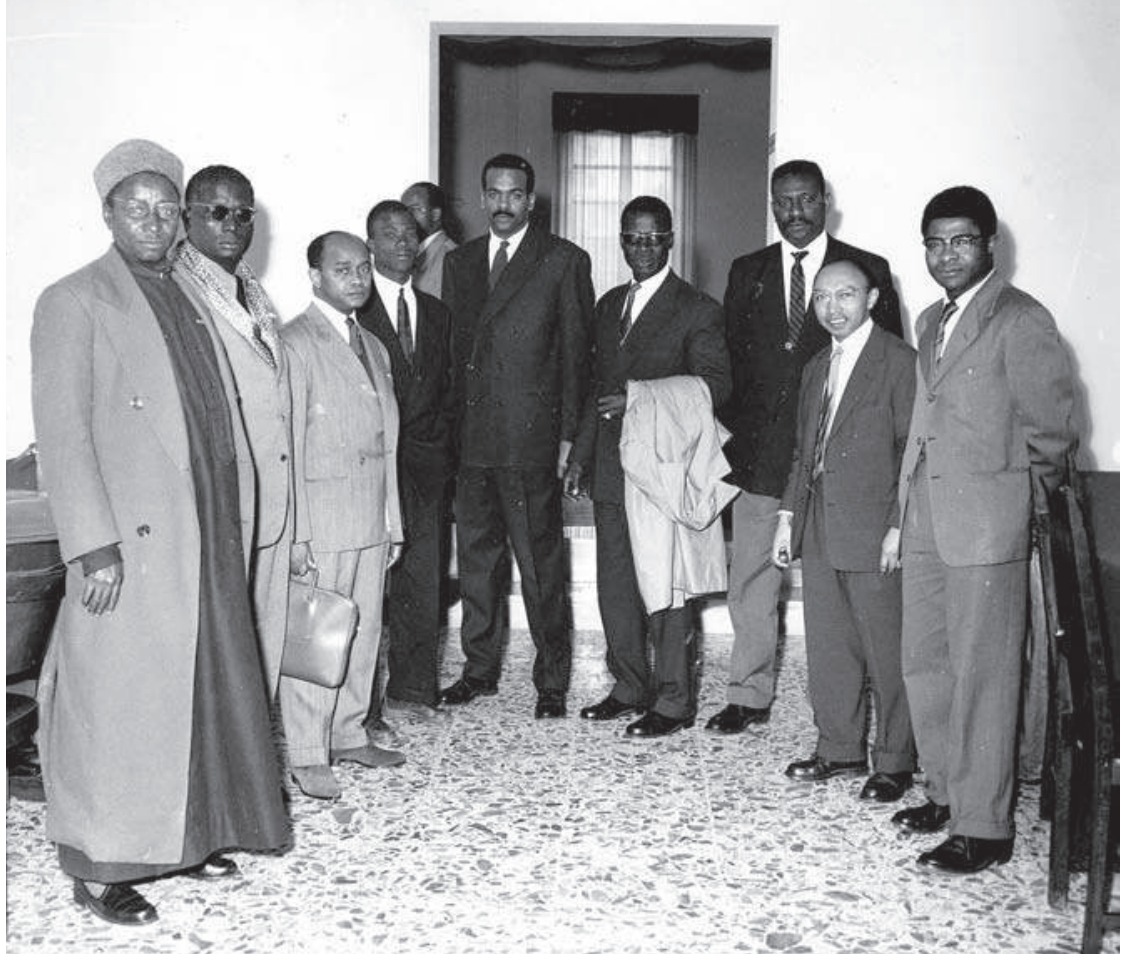

Fig. 6 Participants au Deuxième Congrès des écrivains et artistes noirs à Rome, mars-avril 1959 De gauche à droite : Amadou Hampaté Bâ, Émile Saint-Lot, Jacques Rabemananjara, Louis Behanzin, Édouart Glissant, Bernard Dadié, Cheik Anta Diop, Édouard Andriantsilaniarivo et Bernard Fonlon @ Présence Africaine.

\section{La Société africaine de culture}

Le réseau d'échanges et de diffusion d'idées imaginé par Alioune Diop prend une forme institutionnelle dès 1956 avec la création de la Société africaine de culture (SAC). Cette organisation devait permettre de réaliser certains des objectifs que s'étaient donnés les acteurs du Premier Congrès des écrivains et artistes noirs : "La création de la S.A.C satisfait à un des soucis majeurs du Congrès, celui de constituer un organisme permanent, chargé officiellement de le représenter dans ses diverses activités, de traduire et de faire traduire dans le concret ses vœux et ses décisions, de préparer enfin ses plans de campagne en vue d'autres manifestations ${ }^{29}$. " Il s'agissait de rassembler les intellectuels et artistes noirs du monde entier engagés dans le combat pour la reconnaissance des cultures noires et de la lutte antiraciste et anticoloniale (voir l'article de Romuald Fonkoua et Marc-Vincent Howlett et l'entretien avec Daniel Maximin). Sa direction fut confiée à l'ethnologue haïtien Jean Price-Mars. Joséphine Baker appartenait au groupe des vice-présidents. On trouvait par ailleurs dans le conseil exécutif de 1956 plusieurs personnalités intellectuelles et artistiques noires de générations différentes: des Américains avec le musicien Louis Armstrong, le sociologue W. E. B. Du Bois, le chanteur Paul Robeson, le poète Langston Hughes, l'écrivain Richard Wright, la danseuse Catherine Dunham; des Africains : l'acteur Habib Benglia, les écrivains Alexandre Biyidi (Mongo Beti), Amos Tutuola, Hampâthé Bâ, le scientifique Cheikh Anta Diop; des Antillais : le philosophe Frantz Fanon, les poètes Édouard Glissant et Aimé Césaire, l'écrivain René Maran, l'activiste George Padmore; des Malgaches: le poète Jacques Rabemananjara... Alioune Diop en était le secrétaire général.

La première action de la société fut l'organisation du Second Congrès des artistes et écrivains noirs, accueilli officiellement par la ville de Rome en 1959. L'heure n'était plus à l'élaboration d'un inventaire des cultures noires; il s'agissait désormais de penser ensemble une politique culturelle, scientifique et éducative commune autour du thème " Unité et responsabilités ». Plusieurs commissions furent mises en place : littérature, sciences humaines, arts, sciences mathématiques et

-

29. Aujourd'hui, la SAC a été remplacée par la Communauté africaine de culture en 2005. Voir «Constitution de la SAC », Présence Africaine 24-25, 1959. 


\section{LES CONDITIONS NOIRES : UNE GÉNÉALOGIE DES DISCOURS}

\section{-}

30. Ces réunions se tenaient dans les futurs locaux de la librairie, au 25 bis, rue des Écoles. Elles étaient aussi l'occasion de commenter l'actualité politique. Le 11 janvier 1962, par exemple, fut organisé un débat sur « L'unité africaine » rassemblant des intellectuels africains francophones et anglophones.

31. Présence Africaine organisait des journées du livre africain rue Serpente dans la salle des Sociétés savantes, louée près de l'Odéon à Paris.

32. Catalogue des ouvrages publiés par les éditions Présence Africaine, janvier 1962. techniques. À la veille des indépendances, les intellectuels proposaient ainsi de participer aux changements culturels et politiques à venir. La SAC participa ensuite à l'organisation de nombreux événements en Afrique et en Europe : le colloque «Les peuples de Bandoeng et le sous-développement », à Paris en 1958, celui sur «La recherche scientifique et technique et le développement africain », à Abidjan en 1959, le Premier Congrès international des africanistes, à Accra en 1962, la conférence de Malcom X à la Mutualité en 1965, le Premier Festival des arts nègres, à Dakar en 1966, etc. En 1961, le comité parisien de la SAC créa le Club du livre africain, " pour permettre aux étudiants africains de se rencontrer et de discuter librement de leurs opinions en marge d'un livre d'actualité précédemment analysé par l'un d'eux ${ }^{30}$ ». L'actualité éditoriale sur l'Afrique donna également lieu à des ventes temporaires de livres auxquelles étaient invités des écrivains et des chercheurs ${ }^{31}$. Mais c'est à partir de 1962 que Présence ouvrit une librairie au 25 bis rue des Écoles à Paris: "Aujourd'hui, par l'intermédiaire de sa librairie, Présence Africaine se donne une nouvelle tâche : rendre accessibles à tous les ouvrages actuellement disponibles concernant l'Afrique et le Monde Noir ${ }^{32}$. " La SAC mena également des actions pédagogiques et politiques, envoyant ses membres donner des conférences culturelles et politiques dans les universités de province : en 1961, Édouard Glissant représentait la SAC à Reims dans le cadre de la semaine anticolonialiste organisée par l'Union nationale des étudiants de France (Unef); la même année, le camerounais Jean-Baptiste Obama s'exprimait devant des étudiants à la cité universitaire d'Antony autour du thème "Culture et décolonisation». Le journaliste poète béninois Paulin Joachim raconte qu'Alioune Diop les envoyait partout en France pour défendre la négritude. En avril 1962, Joachim donna par exemple, à Montpellier et à Poitiers, deux conférences sur "la foi des poètes de la négritude » devant des membres de la Fédération des étudiants africains de France (FEANF). Enfin, la SAC se développa également dans toute l'Afrique francophone et anglophone. Après les indépendances africaines, la SAC devait être pour les nouveaux dirigeants un outil d'élaboration des politiques culturelles nationales. Généralement, les représentants locaux des comités étaient des membres des jeunes gouvernements. En 1961 furent inaugurées la Société somalienne de culture africaine, dirigée par le ministre de l'Information, la Société kényane de culture africaine, présidée par Jomo Kenyatta, et la Nigeria Society of African Culture, cependant que des sections ouvraient en Guinée et en Mauritanie.

La SAC participa aussi activement à la préparation du Premier Festival des arts nègres (Dakar, 1966) (voir dans ces pages l'article d'Éloi Ficquet et Lorraine Gallimardet). Cet événement concrétisait l'ambition culturelle d'Alioune Diop, définie dès 1948 dans les statuts de l'association Les Amis de Présence Africaine, et renvoyait au projet d'exposition soumis à Paul Rivet la même année. En 1948, en effet, Alioune Diop proposait à Paul Rivet d'organiser un événement vivant au musée de l'Homme pour mettre en valeur auprès des visiteurs les cultures africaines contemporaines :

Il s'agirait donc bien, non du monde noir fossilisé, voué aux musées et aux amateurs de dépaysement, mais du monde noir en marche, de sa volonté d'avenir, c'est-à-dire, en dernière analyse, de son intégration, en tant que continent africain, dans le concert mondial. Cette exposition serait une présence de l'Afrique, et cette formule pourrait être comme le maître-mot de cette manifestation [...]. L'exposition aurait donc moins le caractère d'un musée ou d'un marché que celui d'un 
théâtre ou d'un stade. Elle serait plus une «Jamborée » qu'une exposition coloniale. Donc une exposition vivante, où l'Africain, dans les divers domaines artistiques, culturels, sportifs et sociaux, montrerait ce qu'il est, donc, il aurait plus à jouer qu'à exposer [...]. L'exposition serait la manifestation de cet esprit africain sauvegardé $[\ldots]^{33}$.

La position idéologique n'est pas la même ici que pour le festival de Dakar, mais on constate, de la part d'Alioune Diop, la volonté de montrer une culture africaine vivante. Cet événement n'eut finalement pas lieu, mais, en 1951, Présence Africaine publia un cahier spécial intitulé "L'art nègre" qui avait pour objectif de "montrer la présence africaine dans le domaine esthétique » et de réfléchir " aux problèmes posés par un art africain moderne qui se crée lentement ». C'est à cette occasion que Présence Africaine proposa à Chris Marker et Alain Resnais de réaliser un film sur ce sujet. Les statues meurent aussi sortit en 1953, reçut le prix Jean Vigo et fut censuré jusqu'en 1963.

"À l'origine, c'était un film sur l'art nègre que Présence Africaine nous avait commandé. Avec Chris Marker, nous avons commencé à travailler ; nous n'avions pas au départ l'idée de faire un film anticolonialiste et antiraciste. C'est naturellement que nous avons été conduits à poser quelques questions qui ont valu au film d'être interdit ", écrit Alain Resnais en février 1961 dans Clarté, le journal de la Jeunesse communiste. Et il précise en octobre dans la revue Premier plan : "On nous avait commandé un film sur l'art nègre. Chris Marker et moi sommes partis de cette question : pourquoi l'art nègre se trouve-t-il au Musée de l'homme, alors que l'art grec ou égyptien est au Louvre? »

Mais le Premier Festival des arts nègres fut surtout pensé à partir du congrès de 1959, comme l'expose en détail l'article d'Éloi Ficquet et Lorraine Gallimardet.

L'examen des ambitions et des actions politiques et culturelles d'Alioune Diop nous a montré comment s'est progressivement mis en place un réseau transnational original d'échanges et de diffusion d'idées autour de Présence Africaine, qui a permis de rassembler une part essentielle de la production intellectuelle noire des années 1950-1960; l'étude précise de l'activité éditoriale de Présence Africaine est ici présentée par Romuald Fonkoua et Marc-Vincent Howlett.

À Dakar, en 2004, durant la Première Conférence des intellectuels d'Afrique et de la diaspora, c'est essentiellement en se référant à des textes publiés dans la revue, et plus particulièrement aux actes du Premier Congrès des écrivains et artistes noirs de 1956, que, lors de son intervention « Les intellectuels africains et de la diaspora ", l'historien sénégalais Mamadou Diouf, qui enseigne aujourd'hui aux États-Unis, restitua une histoire complexe et plurielle.

Plus récemment encore, à l'instar de Georges Balandier, Jean-François Bayart (2009) a rappelé ce que les études postcoloniales doivent aux courants intellectuels anticolonialistes des années 1950, citant principalement les auteurs de la bibliothèque constituée par Présence Africaine: Aimé Césaire (Discours sur le colonialisme en 1955, Lettre à Thorez en 1956, "Culture et colonisation » en 1956 [Césaire 1956a], « Décolonisation pour les Antilles » en 1956 [Césaire 1956b]), Frantz Fanon ("Racisme et culture» en 1956, The Damned en 196334) et Jean-Paul Sartre ( Orphée noir » en 1949 [Sartre 1949], "La pensée politique de Patrice Lumumba » en 1963 [Sartre 1963]). Nous pourrions citer également David Diop [D. Diop 1953], Abdoulaye Sadji [Sadji 1949], Léon-Gontran Damas ${ }^{35}$, Édouard Glissant ${ }^{36}$, Jacques Rabemananjara (1959) ou Mongo Beti [Boto 1955].

musée du quai Branly sfs@quaibranly.fr
(1)

33. Archives Michel Leiris, Laboratoire d'anthropologie sociale, $\mathrm{fr} / \mathrm{cdf} / \mathrm{las} / F M L-E$ 01-01-051.

34. Traduction de l'ouvrage publié par Maspéro en 1961.

35. Léon-Gontran Damas, extraits de «Black Label », poèmes qui dénoncent violemment le racisme, Présence Africaine 4, 1948 : 617624.

36. Édouard Glissant coordonne avec Paul Niger le numéro spécial consacré aux Antilles et à la Guyane, Présence Africaine 43, 1962. 
PRESENCE AFRICAINE

LES CONDITIONS NOIRES : UNE GÉNÉALOGIE DES DISCOURS

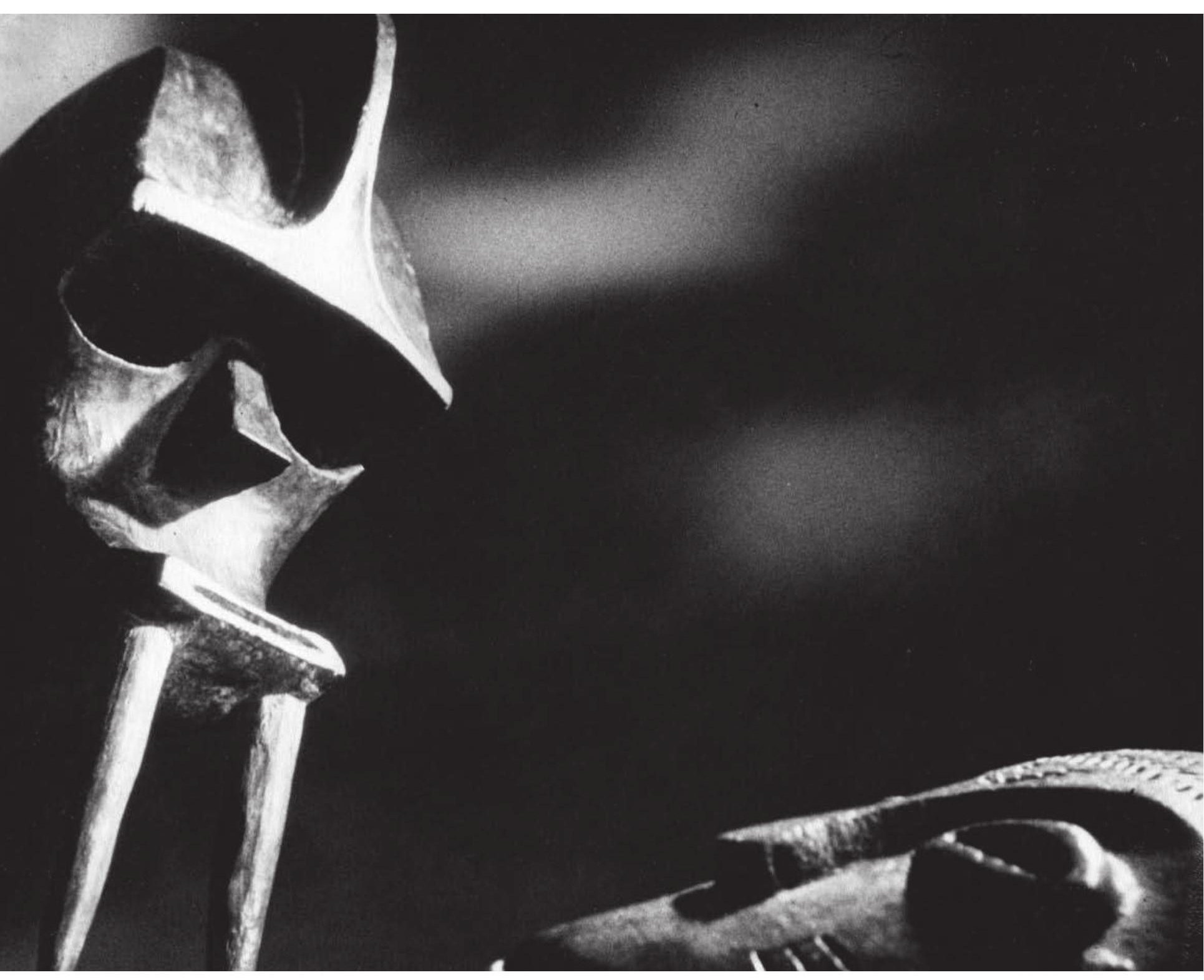

Fig. 7 à 10 Photogrammes

du film Les statues meurent

aussi de Chris Marker et Alain

Resnais, 1953. Iconothèque de la

Cinémathèque française

๑) Présence Africaine. 

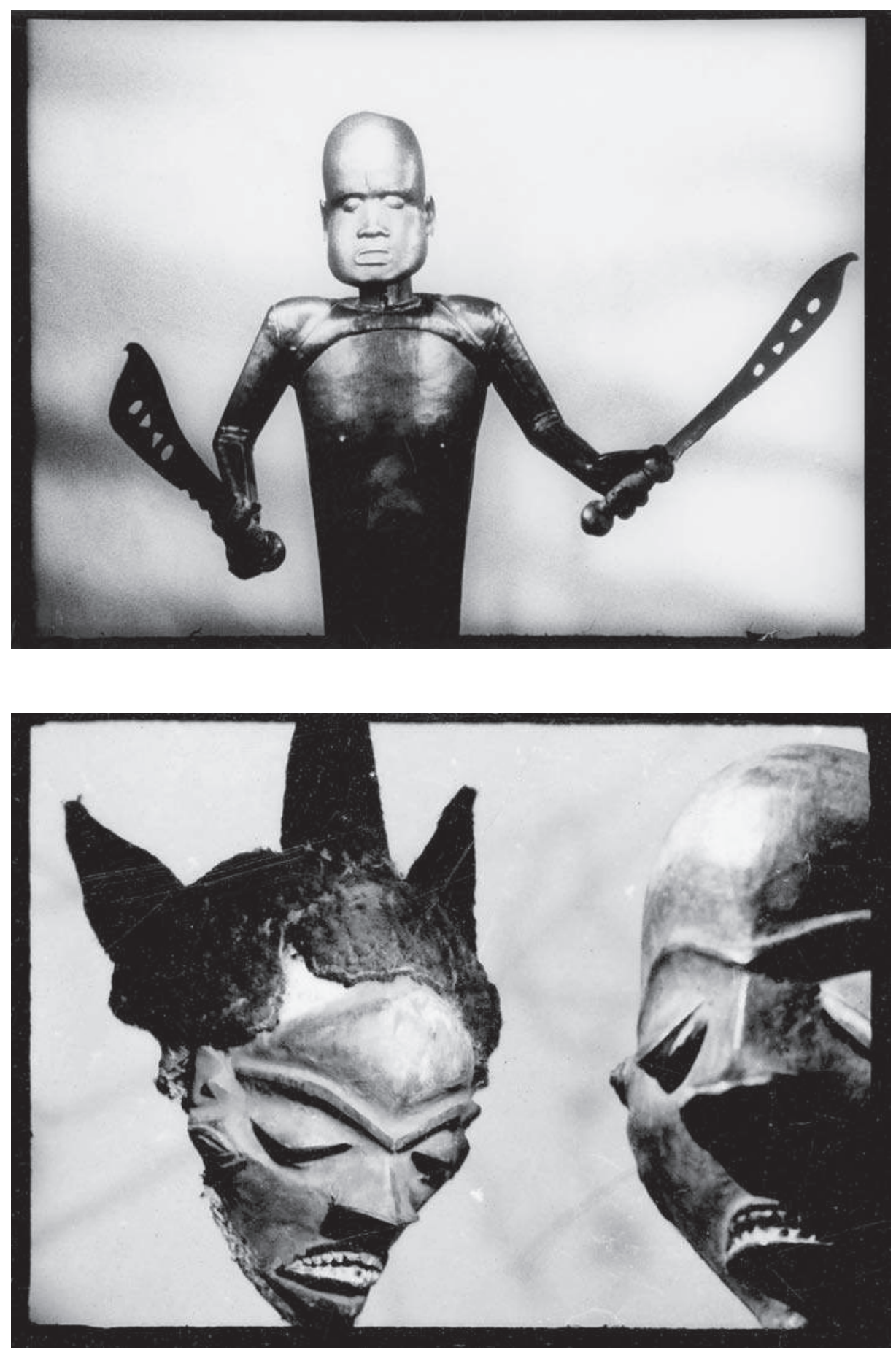

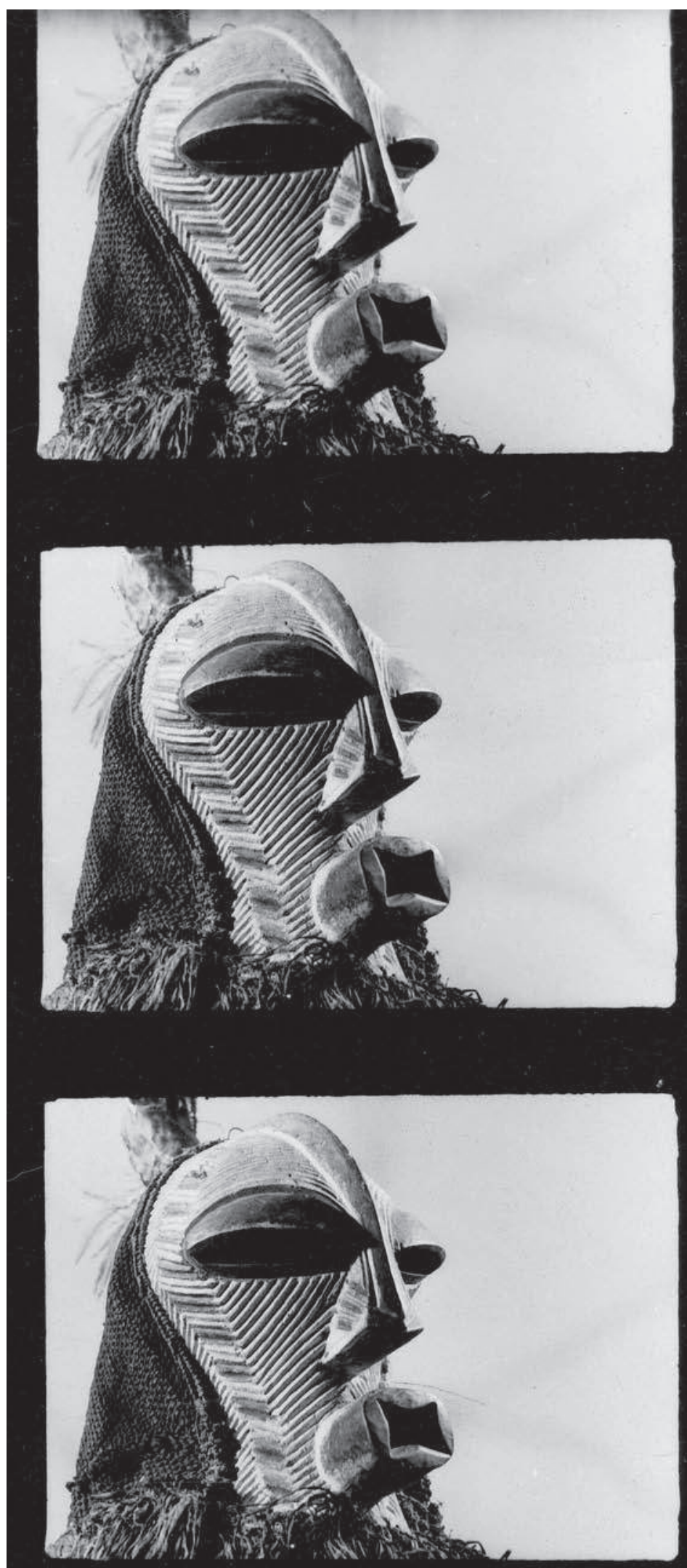


\section{Bibliographie}

\section{Balandier, Georges}

1977 Histoire d'autres. Paris, Stock.

\section{BAYART, Jean-François}

2009 « En finir avec les études postcoloniales », Le Débat 154, mars-avril : 119-140.

\section{Benot, Yves et Dorigny, Marcel}

2000 Grégoire et la cause des Noirs [1789. 1831) : combats et projets. Paris, Société française d'histoire d'outre-mer et Association pour l'étude de la colonisation européenne.

\section{Boto, Eza (Beti Mongo)}

1955 «Ville cruelle », Présence Africaine 16 : 9-158.

\section{Casanova, Pascale}

2008 La République mondiale des lettres. Paris, Seuil.

\section{CÉSAIRE, Aimé}

1956a « Décolonisation pour les Antilles», Présence Africaine, avril-mai : 7-12.

$1956 \mathrm{~b}$ «Culture et colonisation», Présence Africaine, numéro spécial, juin-novembre : 190-205.

Dewitte, Philippe

1985 Les Mouvements nègres en France. Paris, L'Harmattan.

\section{Diop, Alioune}

1947 « Niam n'goura ou la raison d'être de Présence Africaine », Présence Africaine 1 : 7-14.

\section{Diop, David}

1953 «Étudiant africain devant le fait colonial », Présence Africaine 14 : 114-11?.

\section{Dorigny, Marcel et Gainot, Bernard}

1998 La Société des amis des Noirs (17881799). Contribution à l'histoire de l'abolition de l'esclavage. Paris, Unesco.

Du BoIs, William Edward Burghardt 2007 Les Âmes du peuple noir, traduction et édition par Magali Bessone. Paris, La Découverte.
EDWARDs, Brent Hayes

2003 The Practice of Diaspora: Literature, Translation, and Rise of Black Internationalism. Cambridge, Harvard University Press.

FANON, Frantz

1956 «Racisme et culture 》, Présence

Africaine, numéro spécial, juin-novembre : 122-131.

1961 The Damned. Paris, Présence Africaine.

Gilroy, Paul

2003 L'Atlantique noir : modernité et double conscience. Paris, Kargo.

Gueye, Abdoulaye

2006 « De la diaspora noire : enseignement du contexte français », Revue européenne des migrations internationales 22, 1 : 11-33.

\section{HoFFMAN, Léon-François}

1987-1988 « Victor Hugo, John Brown et les Haïtiens », Nineteenth-Century French Studies $17: 47-58$.

\section{Locke, Alain Leroy}

2009 Le Rôle du Nègre dans la culture des Amériques, présentation par Anthony Mangeon. Paris, L'Harmattan.

Mangeon, Anthony (dir.)

2008-2009 «Harlem Heritage, mémoire et renaissance », Riveneuve Continents, hors-série.

\section{NARDAL, Paulette}

1932 «Éveil de la conscience de race», Revue du monde noir, numéro 6 .

\section{PADMORE, George}

1956 Panafricanisme or Communism? The Coming Struggle for Africa, préface de Richard Wright. Londres, Dobson.

\section{Person, Yves}

1979 « Le Front populaire au Sénégal (mai 1936 - octobre 1938) », Le Mouvement social 107 : ?7-101.

\section{RABEMANANJARA, Jacques} 1959 Nationalisme et problèmes malgaches. Paris, Présence Africaine.
SADII, Abdoulaye

1949 «Littérature et colonisation 》, Présence Africaine 6 : 139-141.

SARTRE, Jean-Paul

1949 « Orphée noir » (extraits),

Présence Africaine 6 : 9-14.

1963 «La pensée politique de Patrice Lumumba », Présence Africaine, $3^{\mathrm{e}}$ trimestre : 18-58.

Smouts, Marie-Claude (dir.) 2007 La Situation postcoloniale : les «postcolonial studies » dans le débat français, Actes du colloque organisé par le Centre d'études et de recherches internationales les 4 et 5 mai 2006, préface de Georges Balandier. Paris, Les Presses de Sciences Po.

\section{StAdLeR, Katherina}

1998 « Genèse de la littérature afrofrancophone en France entre les années 1940 et 1950 », Mots pluriels 8, octobre.

Premier Congrès international des écrivains et artistes noirs (Paris, Sorbonne, 19-22 septembre 1956) 1956 Présence Africaine, numéro spécial, juin-novembre.

Deuxième Congrès des écrivains et artistes noirs

(Rome, 26 mars- - $^{\mathrm{er}}$ avril 1959)

1959a T. I: «L'Unité des cultures négroafricaines », Présence Africaine, numéro spécial, février-mai.

Deuxième Congrès des écrivains et artistes noirs

(Rome, 26 mars- $1^{\mathrm{er}}$ avril 1959)

1959b T. II : «Responsabilités des hommes de cultures », Présence Africaine, numéro spécial, août-novembre.

Hommage à Alioune Diop 1977 Hommage à Alioune Diop, fondateur de «Présence Africaine » : trentième anniversaire de «Présence Africaine », 1947-1977, textes réunis par la Société africaine de culture. Rome, Éditions des amis italiens de «Présence Africaine ». 